\title{
In memoriam: Professor Timothy William Evans
}

\author{
Julian Bion * (D)
}

๑ 2018 Springer-Verlag GmbH Germany, part of Springer Nature

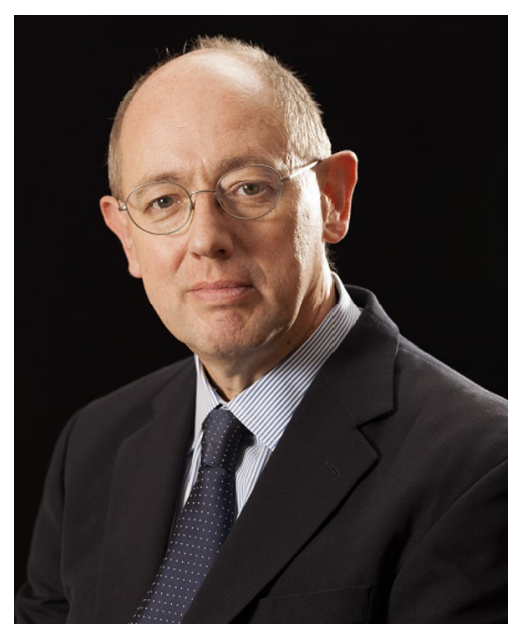

Tim Evans's initial career ambition to be a pilot in the Royal Navy was thwarted by the discovery that he was colour-blind. On this unexpected setback he built a lifetime of success in intensive care and respiratory medicine, research, and health services development.

Tim Evans was born in Chorleywood, Hertfordshire on May 29th 1954, and attended High Storrs School in Sheffield where he excelled in academic, musical and sporting activities, combining rugby and cycling with being a chorister. He obtained A-levels in English, History and Economics and was offered a place at the London School of Economics. However, he experienced a minor epiphany when a summer job as a hospital porter convinced him to pursue a career in medicine. To do

\footnotetext{
*Correspondence: j.f.bion@bham.ac.uk

University Department of Intensive Care Medicine, University

of Birmingham, Ground Floor East Wing, Heritage Building, Queen
}

Elizabeth Hospital, Birmingham B15 2TH, UK

this he had to gain the necessary foundations in science A-levels. He applied for and successfully completed the one-year (1st $\mathrm{MB}$ ) basic science conversion course at Manchester, allowing him to join the 2nd MB medical course. In his second year Tim became Sacristan to the chapel of St Anselm Hall and then secretary of the junior common room of the Hall, not for the usual one year, but for two, a unique distinction reflecting his ability to combine administrative excellence with focus, inclusiveness and wit, qualities he continued to demonstrate for the rest of his professional life. A contemporary recalls "a man of tremendous drive, application and resilience: a deeply principled person whose radical change of career path reflected his commitment to the greater good, though he would never have been so vulgar or pompous as to express it in those terms himself."

Tim's high intelligence was obvious during his undergraduate training: he obtained multiple prizes, a university scholarship, a Medical Research Council award, and a BSc honours degree in psychology, and he graduated with honours in medicine in 1979, coming second in his year of 270 students. Following post-registration medical training in London he completed a $\mathrm{PhD}$ at the University of Sheffield on the mechanisms of cor pulmonale. From 1984 to 1986 he was awarded an MRC travelling fellowship to study at the Cardiovascular Research Unit of the University of California San Francisco, returning to London in 1985 to undertake higher training in pulmonary and critical care medicine, the only discipline which could simultaneously satisfy his interests in applied cardiorespiratory physiology, research and acute patient care.

In 1987 he was appointed Consultant in Intensive Care \& Thoracic Medicine at the Royal Brompton Hospital, London. In 1990 he was awarded an MD from the University of Manchester, and in 1996 was promoted to a Professorial Chair of Intensive Care Medicine by Imperial College London, one of the first such academic posts

\section{实 Springer}


in this new speciality. He was appointed honorary Consultant in Intensive Care Medicine to the Army in 1997, a post he retained until his death, receiving the Guthrie Medal in 2015 for distinguished service by a civilian consultant. In addition to front-line clinical duties, in 2004 he became Medical Director of the Royal Brompton \& Harefield Hospitals NHS Trust, and from 2006 to 2015 deputy Chief Executive, overseeing a major reorganisation of specialist services and the introduction of the extracorporeal membrane oxygenation (ECMO) service-one of only five such centres to be commissioned in the UK. He was also director of $R \& D$ at the Trust. He acquired the Fellowship of the British Association of Medical Managers in 2006.

As a clinician Tim demanded excellence of himself and inspired it in others. His knowledge was encyclopaedic. He combined evidence-based practice with bedside teaching at every opportunity, and had a remarkable ability to convey complex concepts with clarity. He valued nursing staff and other members of the clinical team in the intensive care unit as true partners, and encouraged them to be advocates for the patients and their relatives. By seeking their opinions and ensuring their involvement he bound them together with a common purpose. He knew the names of all staff in the hospital, and was genuinely interested in their lives: the effect was to create a sense of community and loyalty which translated into better patient care. As one of his colleagues said, speaking for all: 'Men like Tim come once in a generation'.

Tim's research focused particularly on the pathogenesis of acute lung injury and inflammation. He published more than 300 original scientific articles, authored eight textbooks, and obtained a large number of prestigious competitive research grants. He supervised at least 35 $\mathrm{PhD}$ and MD students by whom he was regarded with considerable respect and admiration, creating the next generation of researchers. At national and international level he was a key opinion leader in supporting the early development of international research in intensive care medicine through multiple professional organisations and research groups who appreciated his deep insights into complex issues, his capacity to unite clinical and research perspectives, and his pragmatism. At conferences his lectures guaranteed a packed auditorium. In leadership roles he was focused, strategic, decisive, and generous. As a collaborator he was always reliable, supportive, and insightful. In 1999 he was elected Fellow of the Academy of Medical Sciences, and in 2010 was awarded the status of Clinical Senior Investigator by the National Institute of Health Research.

Tim was the Academic Registrar and then Academic Vice-President of the Royal College of Physicians between 2005 and 2012. He would always prepare the path for his successors with consideration and kindness: a rare combination of interpersonal skills and high intelligence. He was appointed Lead Fellow for the Future Hospital Commission of the Royal College of Physicians (2012-2013) and Editor in Chief of the Future Hospital Journal (20132016). In both of these roles he was the primary mover and visionary. He was Chair of the National Cardiac Benchmarking Collaborative (2014-2016), a Trustee of the Faculty of Pharmaceutical Medicine since 2012 (and awarded honorary Fellowship of the Faculty in November 2018), and Board member and Trustee of the Nuffield Trust since 2014. In 2016 Tim was appointed National Director for Clinical Productivity at the Department of Health, working on delivery of the 'Getting It Right First Time' programme, to minimise undesirable variation in service delivery across the NHS, an ambition to which he was wholly committed. Despite this schedule he continued to provide extraordinary mentorship and friendship to his colleagues at the Royal Brompton Hospital.

To this list of remarkable achievements are those specifically related to the establishment of the Faculty of Intensive Care Medicine and of ICM as a primary speciality. In 2010 the immediate past-President of the Royal College of Anaesthetists (RCoA), Dr Judith Hulf, convened a meeting of three individuals to discuss the formation of a new multi-speciality Faculty for ICM: Julian Bion, Alasdair Short, and Tim Evans. Tim was instrumental in securing the active support of the Royal College of Physicians for this initiative. Tim would have been an outstanding candidate for first Dean of our Faculty, but instead chose to stand back to allow Julian Bion as representative of the lead College to have that honoura typically generous gesture. As first Vice-Dean Tim was immensely supportive: his experience, wisdom, and hard work during the first three years were fundamental to the success of the Faculty, and his consideration for others created a sense of community. The award of the Faculty's Gold Medal in October 2018 demonstrated the respect and affection in which he was held by all his colleagues.

In 2016 whilst chairing a meeting Tim experienced an auditory aura which he recognised as being of temporal lobe origin. An MRI scan that afternoon revealed a likely glioblastoma. This was confirmed at surgery. He returned to work despite undergoing chemotherapy and radiotherapy. It was characteristic of the man that many friends and colleagues were unaware of his illness, because despite this burdensome treatment course he continued to fulfil his duties as national clinical director. Remission was short-lived, and the tumour recurred after 18 months. He elected not to undergo further treatment. Despite a hemiparesis confining him to a wheelchair, he contended with this catastrophe without the slightest trace of self-pity and with retention of his robust sense 
of humour while continuing to keep in touch with his team at the Department of Health. He remained thoughtful of, and interested in, the welfare and activities of others, retaining his remarkable intellectual capacities to the end. In his life, in his work, and throughout his illness he was supported by his wife Emer, a distinguished neuroradiologist, and their four children. He died peacefully at St Joseph's Hospice with them present, on November 9th 2018.

Tim satisfied his desire for aviation by acquiring a private pilot's licence. He was also an accomplished sailor. His skills in aerial and aquatic navigation were matched by his ability to negotiate the tide of human affairs, whether speaking with a bereaved family or a government minister. A Benthamite in terms of human happiness, he would draw attention to the statement inscribed on a memorial plaque to a Victorian pharmacist in his local parish church of St Edmund's in Southwold: 'He went about doing good'. He concluded his personal statement as candidate for the presidency of the Royal College of Physicians with the following words: "The College must be resolutely patient-centred in everything that it does". These words were not empty rhetoric, but the compass by which he directed his professional life. His early death has deprived us of a transformativeleader, a compassionate physician, an internationally recognised researcher, an outstanding colleague, a loving husband and father, and good friend.

\section{Acknowledgements}

With valuable contributions from Dr Emer Macsweeney, Mr Patrick Burns, Mr Arthur Mawby, Professor Mike Polkey, Dr Cliff Morgan, Professor Susanna Price, Professor John Wass, Professor Richard Beale, Dr Jeremy Henning, Mr Tom Grinyer, Dr Ganesh Suntharalingam, Dr Carl Waldmann, Mr Daniel Waeland, Professor Tim Briggs, Professor Marco Ranieri, Professor Art Slutsky, Professor Elie Azoulay, Dr Gary Masterson and Professor Mervyn Singer.

Received: 9 December 2018 Accepted: 10 December 2018 Published online: 18 December 2018 